\title{
Glutathione Is Required by Rhizobium etli for Glutamine Utilization and Symbiotic Effectiveness
}

\author{
Rosarita Taté, ${ }^{1}$ Michele Cermola, ${ }^{1}$ Anna Riccio, ${ }^{1}$ Graciana Diez-Roux, ${ }^{2}$ and Eduardo J. Patriarca ${ }^{1}$ \\ ${ }^{1}$ Institute of Genetics and Biophysics, 'A. Buzzati-Traverso', CNR, Naples, 80131, Italy; ${ }^{2}$ Telethon Institute of Genetics and \\ Medicine (TIGEM), Naples, 80131, Italy
}

Submitted 13 June 2011. Accepted 7 October 2011.

\begin{abstract}
Here, we provide genetic and biochemical evidence indicating that the ability of Rhizobium etli bacteria to efficiently catabolize glutamine depends on its ability to produce reduced glutathione (L- $\gamma$-glutamyl-L-cysteinylglycine [GSH]). We find that GSH-deficient strains, namely a gshB (GSH synthetase) and a gor (GSH reductase) mutant, can use different amino acids, including histidine, alanine, and asparagine but not glutamine, as sole source of carbon, energy, and nitrogen. Moreover, L-buthionine $(S, R)$-sulfoximine, a GSH synthesis inhibitor, or diamide that oxidizes GSH, induced the same phenotype in the wild-type strain. Among the steps required for its utilization, glutamine uptake, occurring through the two well-characterized carriers (Aap and Bra systems) but not glutamine degradation or respiration, was largely reduced in GSH-deficient strains. Furthermore, GSH-deficient mutants of $\boldsymbol{R}$. etli showed a reduced symbiotic efficiency. Exogenous GSH was sufficient to rescue glutamine uptake or degradation ability, as well as the symbiotic effectiveness of GSH mutants. Our results suggest a previously unknown GSH-glutamine metabolic relationship in bacteria.
\end{abstract}

The tripeptide glutathione (L- $\gamma$-glutamyl-L-cysteinylglycine [GSH]) is considered the most potent antioxidant produced by living cells. Usually, GSH is synthesized from the constituent amino acids by two ATP-dependent consecutive reactions catalyzed by two enzymes (i.e., $\gamma$-glutamylcysteine synthetase [EC 6.3.2.2] and GSH synthetase [EC 6.3.2.3], encoded by the gshA [GSH1] and $g s h B$ [GSH2] genes, respectively).

Based on the characterization of strains unable to synthesize GSH ( $g \operatorname{sh} A$ and $g \operatorname{sh} B$ mutants) or depleted of intracellular GSH by using either L-buthionine $(S, R)$-sulfoximine (BSO), a specific inhibitor of GSH synthesis, or diamide, a thiol-oxidizing reagent, it was established that Escherichia coli cells i) require GSH when subjected to chemical or physical challenges such as radiation, osmotic shock, selenite, chlorine compounds, formaldehyde, acidic conditions, and electrophilic chemicals (i.e., methylglyoxal or $N$-ethylmaleimide) (Masip et al. 2006); ii) do not require GSH to grow efficiently in a chemically defined minimal medium and, therefore, for physiological cellular processes, including transport, transcription, and translation, such as in yeast and in mammalian cells (Greenberg and Demple 1986; Meister 1988).

Conversely, it has been shown that Rhizobium bacteria (namely, Rhizobium tropici, Sinorhizobium meliloti, and Bradyrhizobium spp.) require GSH not only to survive chemical or

Corresponding author: E. J. Patriarca; Telephone: +39-0816132431. Fax: +39-0816132706. E-mail: eduardo.patriarca@igb.cnr.it physical challenges but also to grow in a chemically defined minimal medium (thus, in the absence of noticeable environmental stresses) (Harrison et al. 2005; Ricillo et al. 2000; Sobrevals et al. 2006). Rhizobia are gram-negative soil bacteria able to reduce $\mathrm{N}_{2}$ (nitrogen fixation) in symbiotic association with legume plants, and it was established that their symbiotic proficiency depends on their capacity to synthesize GSH (Harrison et al. 2005; Pauly et al. 2006; Sobrevals et al. 2006). Notably, it has been recently reported that nodules induced by a GSH-deficient mutant of $R$. tropici on the root of Phaseolus vulgaris undergo early senescence (Muglia et al. 2008). Nevertheless, the cellular processes regulated by or dependent on GSH in either free-living rhizobia or $\mathrm{N}$-fixing bacteroids (their intracellular symbiotic form) remain unknown.

In this study, we identify an intricate GSH-glutamine (Gln) metabolic relationship in $R$. etli. In searching for mutant strains unable to utilize Gln as sole source of carbon (C) and nitrogen (N), we substantiate our previous findings (Taté et al. 2004) supporting the idea of a strict GSH dependence of Gln catabolism in $R$. etli. Moreover, we show that Gln transport or uptake is the defective step of Gln utilization in GSH-deficient strains. Most remarkably, and unexpectedly, we provide evidence that Gln could delay or inhibit the growth of bacteria depending on the GSH status. All together, our data provide new insights on the role of GSH in free-living rhizobia and may be relevant for the efficiency or maintenance of its symbiotic form.

\section{RESULTS}

Isolation of a $g \operatorname{sh} B:$ Tn5 mutant by seeking for GIn-deficient mutants.

Tn5-induced mutants, derivative of the strain CE3 (wild type) of $R$. etli and unable to grow with Gln as sole source of $\mathrm{C}$ and $\mathrm{N}$, were isolated and named CE3 Tn5 Gln utilization (CTGUT) mutants, as was previously done (Taté et al. 2004). Here, by means of a round of ampicillin-enrichment routines, four mutant strains affected in Gln but in neither glucose (Glc) nor in succinate (Suc) utilization were isolated. At first, exploiting the kanamycin-resistance cassette, the Tn5-flanking genomic DNA regions were cloned from all the mutants isolated. A DNA sequence analysis revealed that, among these mutants, only one strain, CTGUT43, was mutated in a gene that was not previously identified as required for Gln utilization (Taté et al. 2004). Indeed, strain CTGUT43 carried a single Tn5 insertion in an open reading frame (948 nucleotides, 316 codons) sharing up to $100 \%$ identity (over 315 -amino acid overlap) with GSH synthetase (encoded by $g s h B$ ) from various bacteria, including strain CFN42 of R. etli (RhizoBase: RHE_ CH00322; National Center for Biotechnology Information: NC_007761.1), R. tropici, and S. meliloti (Gonzalez et al. 
2006; Harrison et al. 2005; Ricillo et al. 2000). GshB enzyme catalyses the second step of GSH biosynthesis (i.e., the conversion of $\gamma$-glutamylcysteine ( $\gamma$-GluGly) and Gly into GSH. The growth defects of strain CTGUT43 were prevented either by adding exogenous GSH $(100 \mu \mathrm{M})$ or upon transformation with the plasmid pAR367 (strain CTGUT43-pAR367) (Fig. 1A). This plasmid harbors the $g s h B$ gene and its proximal $5^{\prime}$ flanking region (159 bp upstream from the ATG initiation codon) that was polymerase chain reaction (PCR) amplified using specific oligonucleotides (discussed below). As expected, strain CTGUT43 showed a high susceptibility to electrophilic chemicals (methylglyoxal and $N$-ethylmaleimide) and acidic conditions compared with strains CE3 and CTGUT43-pAR367 (data not shown). Altogether, these data indicated that the phenotype of strain CTGUT43 was a consequence of $g s h B$ gene disruption and, accordingly, strains CTGUT43 and CTGUT43-pAR367 were named CTGUT43 $\left(g s h B^{-}\right)$and CTGUT43 $\left(g \operatorname{shB}^{-/+}\right)$, respectively.

\section{Growth behavior of the $g \operatorname{sh} B$ mutant.}

The strain CTGUT43 $\left(g s h B^{-}\right)$grew more slowly than strains CE3 and CTGUT43 $\left(g s h B^{-/+}\right)$in all the growth media assayed. For instance, in liquid TYR medium, strains CE3, CTGUT43 $\left(g s h B^{-}\right)$, and CTGUT43 $\left(g s h B^{-/+}\right)$grew with a doubling time of 150,246 , and $162 \mathrm{~min}$, respectively. In solid rhizobia minimal medium (RMM), the $g s h B$ mutant grew with usual sources of
C, such as Glc or Suc, as well as with different amino acids, including histidine (His), alanine (Ala), or asparagine (Asn), as sole source of $\mathrm{C}$ and $\mathrm{N}$ (Fig. 1A). Notably two different GSHdeficient mutants of $R$. etli, strain CTGUT43 $\left(g s h B^{-}\right)$and a previously isolated mutant, strain CTGUT15(gor $\left.{ }^{-}\right)$, lacking GSH reductase enzyme (Taté et al. 2004), shared the same specific phenotype (Fig. 1A) (i.e., the incapacity to grow on RMMagar supplemented with $5 \mathrm{mM}$ Gln [or Glu] as sole source of $\mathrm{N}$ and $\mathrm{C}$ ). The same growth phenotype was observed when GSH-deficient mutants were spotted at a density of $10^{3}$ to $10^{5}$ bacteria/ $\mu$ l (data not shown).

\section{Which step of Gln utilization is impaired in GSH-deficient mutants?}

In principle, a bacterium may utilize exogenous Gln as a source of $\mathrm{C}$ or energy by means of a four-step process: uptake, deamidation (Gln to Glu), oxidative deamination (Glu to $\alpha$-ketoglutarate), and respiration through the citric acid cycle $\left(\mathrm{CO}_{2}\right.$ production) (Fig. 2). In R. etli, Gln uptake depends on the Aap and Bra transport systems pertaining to the ABC permease family (Hosie et al. 2002; Taté et al. 2004; Walshaw and Poole 1996), whereas Gln degradation requires the activity of two enzymes (i.e., glutaminase and glutamate dehydrogenase [Gdh] (Huerta-Saquero et al. 2004; Taté et al. 2004). Likewise, Glu utilization occurs through the same pathway (Aap/Bra $\rightarrow$ Gdh), excluding the step catalyzed by Gls (Fig. 2). Hence, to
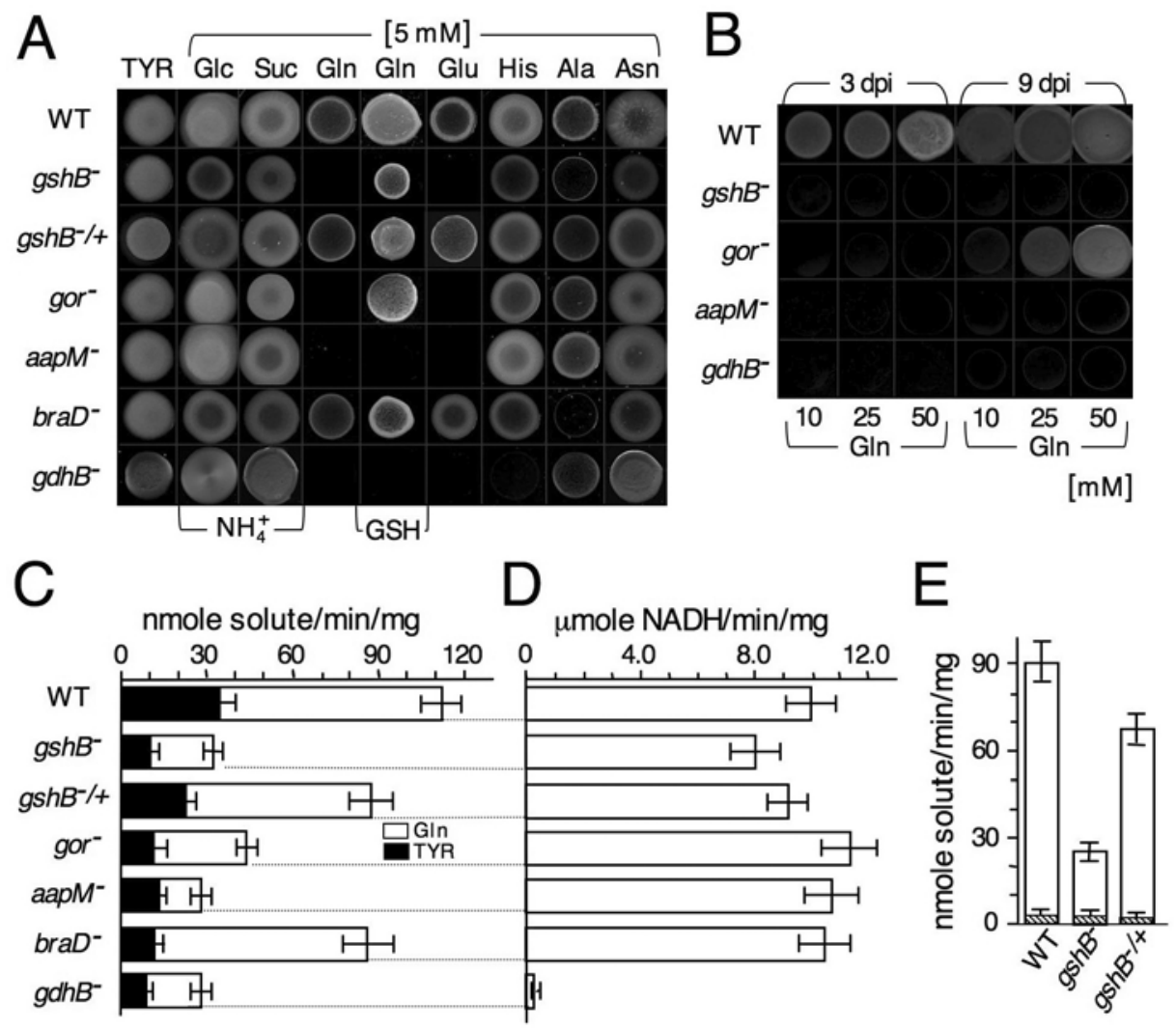

Fig. 1. Glutamine (Gln) utilization, transport, and respiration of glutathione (GSH)-deficient mutants of Rhizobium etli. A, Growth phenotype. Cells (10 4 in 5

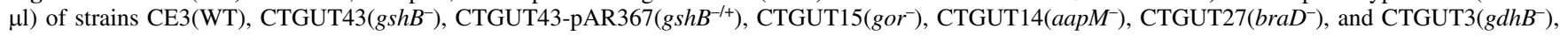
indicated to the left, were spotted onto either complete medium (TYR agar) or minimal medium (rhizobia minimal medium [RMM] agar) (indicated at top) containing $5 \mathrm{mM}$ Gln, Glu, histidine (His), alanine (Ala), or asparagine (Asn) as sole C and N source; or onto RMM agar containing either 5 mM glucose (Glc) or $5 \mathrm{mM}$ succinate (Suc) plus $5 \mathrm{mM} \mathrm{NH} \mathrm{NCl}_{4}$ as $\mathrm{C}$ and $\mathrm{N}$ source, respectively. At a plate of RMM-Gln, $100 \mu \mathrm{M}$ GSH (bottom) was added. Bacterial colonies at 3 days postinoculation $(\mathrm{dpi})\left(30^{\circ} \mathrm{C}\right)$ were individually photographed and displayed as a panel. B, Effect of Gln concentration (bottom) on the growth of $R$. etli mutants (left). Colonies at 3 and 9 dpi (top) are shown. C, Gln uptake activity of $R$. etli strains (left) was measured either before (TYRgrown cells, black bars) or after (white bars) the shift to RMM-Gln medium. D, Glutamate dehydrogenase (Gdh) activity measured in crude extracts prepared from cells incubated in RMM-Gln. E, Gln respiration capacity of $R$. etli strains (bottom) incubated in RMM-Gln with (dashed bars) or without (white bars) fluoricitrate addition $(100 \mu \mathrm{M})$. Values denote nmoles of Gln degraded to $\mathrm{CO}_{2}$. In $\mathrm{C}$, D, and E, data represent the means of three experiments and standard deviations are indicated by error bars. 
get insight into the GSH-Gln relationship, the growth phenotype of a group of $R$. etli mutants (Table 1) was comparatively analyzed (Fig. 1A). Notably, both gshB and gor mutants could not even grow with Glu (Fig. 1A); thus, a putative falling of glutaminase expression or activity in a GSH-deficient background was promptly excluded. Likewise, Gdh activity seemed to be unrelated to GSH metabolism. The utilization of His as sole C source strictly depends on Gdh activity (His is converted into Glu) (Fig. 2) and, indeed, GSH-deficient mutants ( $g s h B$ and gor mutants), unlike strain CTGUT3 $\left(g d h B^{-}\right)$, an $R$. etli mutant lacking Gdh (Taté et al. 2004), were able to grow with His as sole C source (Fig. 1A). Finally, in order to grow on solid RMM-Gln (or Glu), the Aap transport system was required, whereas the Bra system was dispensable, as shown by the mutants CTGUT14 $\left(\right.$ aapM $\left.^{-}\right)$and CTGUT27 $\left(\right.$braD $\left.^{-}\right)$, respectively (Fig. 1A). All together, this phenotypic analysis led us to hypothesize a putative requirement of GSH in the Gln uptake process, likely occurring through the Aap permease. As expected, GSH-deficient strains, unlike $g d h B$ and aapM mutants, grew on RMM-Gln when supplemented with $100 \mu \mathrm{M}$ GSH (Fig. 1A). Notably, the growth ability of the gor mutant but not that of the $g s h B$, aapM, and $g d h B$ mutants was recovered to some extent by increasing the Gln concentration up to $50 \mathrm{mM}$ (Fig. 1B); thus, suggesting that Gln concentration was not the growth-limiting factor for the $g \operatorname{sh} B$ mutant.

\section{Effect of GSH metabolism on GIn transport.}

Thus, we went on to assess and compare the Gln uptake capacity of $R$. etli strains. Because most of the mutants analyzed could not grow in RMM-Gln (Fig. 1A), R. etli strains were grown in TYR (up) to exponential growth phase and then shifted for $2 \mathrm{~h}$ to RMM-Gln. The Gln uptake activity of strain CE3 increased (approximately 3.5-fold) after incubation in RMM-Gln (Fig. 1C). Gln uptake in the $g \operatorname{sh} B$ mutant was also induced (almost threefold), even though the activity values were lower (reduced by $70 \%$ ) compared with those of strain
CE3 under both growth conditions (Fig. 1C). Determination of the CFU showed that the $g s h B$ mutant viability did not change (100\% survival) after shifting to RMM-Gln. Furthermore, plasmid pAR367 $(g s h B)$ reestablished (up to 80\%) the Gln uptake capacity of the gshB mutant (Fig. 1C). Conversely, R. etli strains shifted to $\mathrm{RMM-Suc} / \mathrm{NH}_{4}{ }^{+}$or $\mathrm{RMM}-\mathrm{Glc} / \mathrm{NH}_{4}{ }^{+}$displayed a Gln uptake activity similar to or slightly (up to 20\%) lower than the activity of TYR-grown bacteria. Therefore, the induction of Gln uptake occurred when Gln became the sole source of $\mathrm{C}$ and $\mathrm{N}$ available. Furthermore, analyzing the aapM and braD mutants and assuming a functional autonomy when co-expressed, the relative contribution of Bra and Aap systems to the whole Gln uptake activity $(110 \mathrm{nmol} / \mathrm{mg} / \mathrm{min}$ displayed by strain CE3) was approximately $25 \%(27 \mathrm{nmol} / \mathrm{mg} / \mathrm{min})$ and $75 \%(85 \mathrm{nmol} / \mathrm{mg} / \mathrm{min})$, respectively (Fig. 1C). The activity values of the $g s h B$ and gor mutants were comparable (32 versus $42 \mathrm{nmol} / \mathrm{mg} / \mathrm{min}$ ) and similar to those displayed by the aapM mutant, thus suggesting that the process of Gln uptake is ineffective (i.e., not enough to support Gln catabolism) in GSH-deficient mutants. Finally, strain CTGUT3 $\left(g d h B^{-}\right)$lack-

Table 1. Mutant derivatives of Rhizobium etli CE3 (wild type)

\begin{tabular}{|c|c|c|}
\hline Strain & Mutated gene & Reference \\
\hline CTGUT43 & gshB, glutathione synthetase & This work \\
\hline CTGUT15 & gor, glutathione reductase & Taté et al. 2004 \\
\hline CTGUT3 & $\begin{array}{l}\text { gdhB, NAD-dependent glutamate } \\
\text { dehydrogenase }\end{array}$ & Taté et al. 2004 \\
\hline CTGUT14 & $\begin{array}{l}\text { aapM, amino acid permease (Aap } \\
\text { system) }\end{array}$ & Taté et al. 2004 \\
\hline CTGUT27 & $\begin{array}{l}\text { braD, amino acid permease (Bra } \\
\text { system) }\end{array}$ & Taté et al. 2004 \\
\hline CTNUX10 & gltD, glutamate synthase (GOGAT) & Ferraioli et al. 2002 \\
\hline CFNX247 & $\begin{array}{l}\text { nifA, nitrogenase complex } \\
\text { transcription }\end{array}$ & Girard et al. 1996 \\
\hline CFNX249 & $\begin{array}{l}\text { nifH1/nifH } 2 \text { double mutant, } \\
\text { nitrogenase complex }\end{array}$ & Brito et al 1997 \\
\hline
\end{tabular}

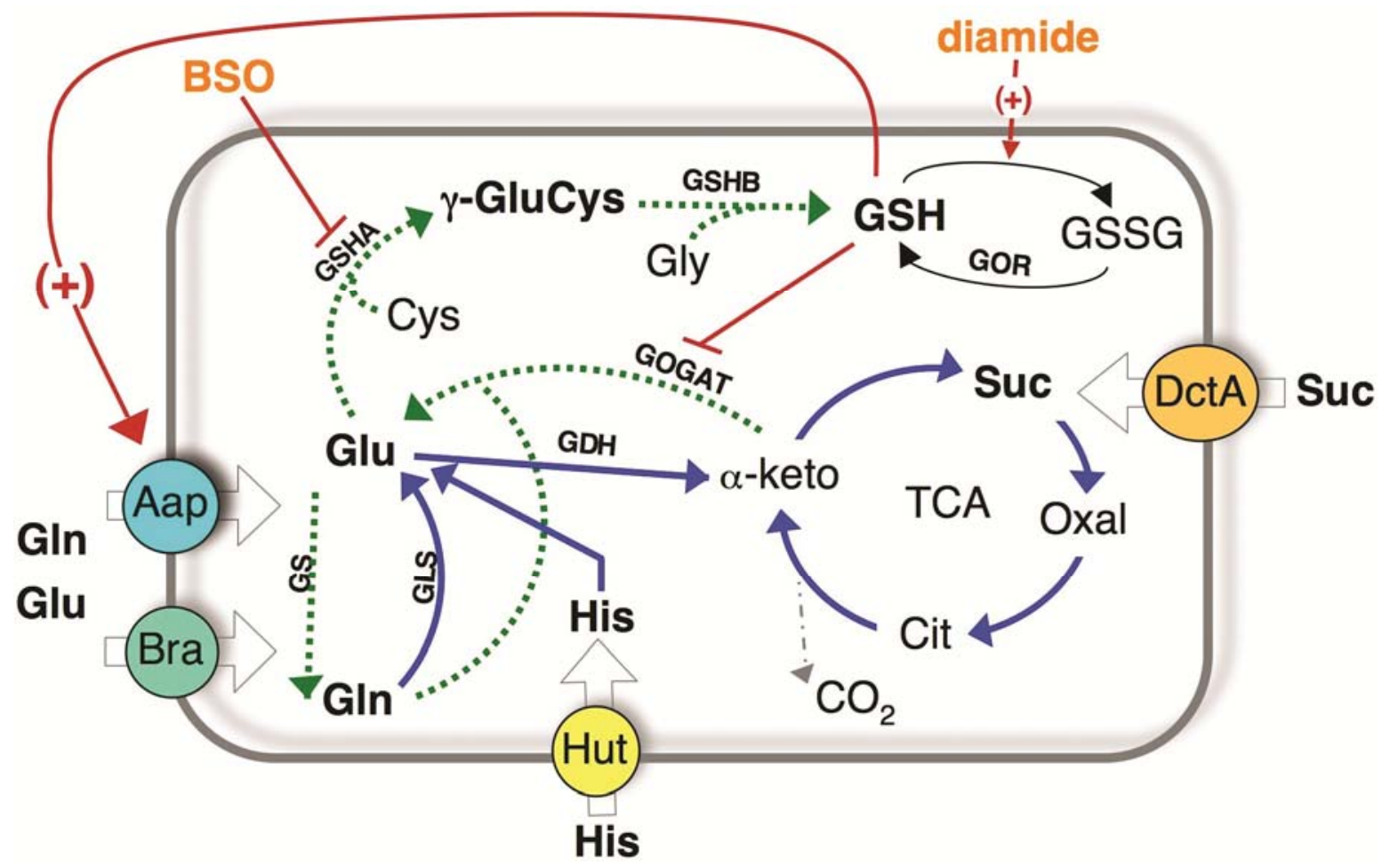

Fig. 2. Metabolic interplay between glutamine $(\mathrm{Gln})$ and glutathione $(\mathrm{GSH})$ in Rhizobium etli is schematically represented. His $=$ histidine, $\gamma \mathrm{GluCys}=\gamma$ glutamylcysteine, $\mathrm{Suc}=$ succinate, $\mathrm{GDH}=$ glutamate dehydrogenase, $\mathrm{BSO}=\mathrm{L}$-buthionine $(S, R)$-sulfoximine. 
ing Gdh activity and, thus, intracellular Glu degradation showed a similarly reduced Gln uptake capacity $(70 \%$ lower than strain CE3). The Gln uptake activity was significantly reduced also by the preincubation of bacteria with inhibitors of the citric acid cycle, namely fluorocitrate and malonate (data not shown). Hence, in $R$. etli, Gln uptake depends not only on the efficiency of Gln carriers (mainly the Aap system) but also on the efficiency of the Glu/Gln catabolic pathways; namely, the Gdh pathway and citric acid cycle (Fig. 2). Indeed, an efficient GSH metabolism appeared to be dispensable for the expresion or activation of both the Gdh pathway and the citric acid cycle, when His became the sole source of C or energy (Fig. 1A).

\section{GIn degradation or respiration in GSH-deficient mutants.}

To rule out a role of GSH on Gdh activity, protein extracts were prepared from $R$. etli mutants and the Gdh activity was measured. Under conditions of induction (cells shifted to RMM-Gln) and considering the Gdh activity (mean value) of strain CE3 as $100 \%$, the activities of strains CTGUT43 $\left(g s h B^{-}\right)$ and CTGUT43 $\left(\mathrm{gshB}^{-/+}\right)$were approximately 80 and $95 \%$, respectively (Fig. 1D). Moreover, Gdh activity displayed by the braD, aapM, and gor mutants were either not significantly different or slightly increased (up to $15 \%$ higher than CE3). Strain CTGUT3 $\left(g d h B^{-}\right)$, used as a control, produced NADH in the presence of Glu at a very low rate (less than $5 \%$ of the CE3 production). Thus, Gdh enzyme was not inhibited by defects in either GSH synthesis or reduction ( $g s h B$ and gor mutants) or Gln transport (aapM and braD mutants).

To evaluate a putative influence of GSH on the last step of Gln utilization, the production of $\mathrm{CO}_{2}$ from Gln (i.e., the flow of Gln through the citric acid cycle) (Fig. 2) was measured. Considering the rate (approximately $90 \mathrm{nmol} / \mathrm{mg} / \mathrm{min}$ ) at which strain CE3 produced $\mathrm{CO}_{2}$ from Gln (Fig. 1E), and assuming that the complete degradation of each Gln molecule occurred, it is possible to conclude that approximately $80 \%$ of the Gln molecules transported were degraded to $\mathrm{CO}_{2}$. Strain CTGUT43 $\left(g s h B^{-}\right)$produced $\mathrm{CO}_{2}$ from Gln at a lower rate $(25$ $\mathrm{nmol} / \mathrm{mg} / \mathrm{min}$ ) compared with strain CE3, even if the fraction of Gln molecules degraded was comparable (approximately $80 \%$ ). Finally, plasmid pAR367 improved Gln respiration capacity of the $g s h B$ mutant (Fig. 1E). As a control, we used fluorocitrate $(100 \mu \mathrm{M})$ and malonate $(2.5 \mathrm{mM})$, which inhibit two enzymes of the citric acid cycle; namely, aconitase and succinate dehydrogenase, respectively (Gardner and Fridovich 1991). These compounds reduced by more than $95 \%$ the capacity of $R$. etli strains, including the $g s h B$ mutant, to produce $\mathrm{CO}_{2}$ from Gln (Fig. 1E). Finally, comparable results were obtained analyzing the gor mutant (data not shown), thus suggesting that the citric acid cycle is active in the GSH-deficient mutants. In correlation, we observed that GSH-deficient mutants grew with arabinose $(5 \mathrm{mM})$ as $\mathrm{C}$ source, and it is known that rhizobia require an efficient citric acid cycle to grow catabolizing arabinose (Walshaw et al. 1997).

\section{Effect of BSO on bacterial growth and GIn uptake.}

It has been previously shown that i) $g \operatorname{sh} B$ mutants accumulate $\gamma$-glutamylcysteine ( $\gamma$ GluCys), the unique intermediate of GSH biosynthesis (Fig. 2); and ii) $\gamma$ GluCys may mask, even if partially, the lack of GSH (Harrison et al. 2005). Hence, to evaluate the occurrence of a putative link between $\gamma$ GluCys and the incapacity to utilize Gln or Glu, we used BSO, an inhibitor of the $\gamma$ GluCys synthetase enzyme (encoded by $g s h A$ ) (Fig. 3A). Remarkably, at BSO concentrations of $500 \mu \mathrm{M}$ to 2 $\mathrm{mM}$, the growth of strain CE3 was i) inhibited on RMM-Gln or RMM-Glu; ii) slightly reduced on RMM-His; or iii) unaffected on either TYR or on RMM with Glc, Suc, or Asn as C source (Fig. 3A). Conversely, $5 \mathrm{mM}$ BSO inhibited strain CE3 in RMM independently of the $\mathrm{C}$ source supplied. The BSOinduced phenotype was rescued by adding GSH $(100 \mu \mathrm{M})$ (data not shown). Furthermore, the growth deficiencies of the gshB mutant were not reverted by BSO treatment (Fig. 3A); in contrast, the lack of $g s h B$ increased bacterial susceptibility to BSO. Actually, $1 \mathrm{mM}$ BSO reduced the growth ability of strain CTGUT43 $\left(g s h B^{-}\right)$in all growth media (Fig. 3A). Finally, strain CTGUT43 $\left(g s h B^{-/+}\right)$was more resistant to BSO than strain CTGUT43 $\left(g s h B^{-}\right)$in all media assayed (Fig. 3A), thus indicating that, in the absence of $g s h B$ (i.e., in the absence of GSH), $\gamma$ GluCys is essential for bacterial growth. Finally, considering that BSO mimics the effect of a $g s h A$ mutation, it is not surprising that a $g \operatorname{sh} A$ mutant was not isolated in the screening performed.

In order to assess the effect of BSO on the Gln uptake capacity of $R$. etli, bacteria were grown in liquid media with or without added BSO (Fig. 3B). Remarkably, $2 \mathrm{mM}$ BSO significantly reduced the ability of the wild-type strain CE3 to use Gln, whereas its ability to use Suc or His, as well as to grow in TYR, was either slightly inhibited or unaffected (Fig. 3B). In correlation, the treatment with BSO reduced by approximately $70 \%$ the capacity of strain CE3 to transport Gln (Fig. 3C). The inhibitory effect of BSO was largely released (reaching approximately $80 \%$ of the maximal level of induction) (Fig. 1C) by shifting the cells ( $2 \mathrm{~h}$ ) to RMM-Gln devoid of BSO. In contrast, BSO-treated cells of the gshB mutant showed almost undetectable Gln uptake activity even after incubation without BSO (Fig. 3C), thus supporting the idea that $\gamma$ GluCys alleviates the mutant deficiency. Furthermore, BSO-treated cells of strains CTGUT14 $\left(\right.$ aapM $\left.^{-}\right)$and CTGUT27 $\left(\right.$braD $\left.^{-}\right)$transported Gln, although at lower rates (up to $70 \%$ ) than BSO-untreated cells (Fig. 3C), thus indicating that BSO similarly inhibited Gln uptake mediated by both Aap and Bra systems.

\section{Effect of diamide on Gln utilization.}

Diamide treatment, by oxidizing thiol groups, depletes cells of reduced GSH (Kosower and Kosower 1995) and may cause the same specific growth phenotype induced by the lack of either $g s h B$ or gor gene (Fig. 3D). In fact, at $250 \mu \mathrm{M}$ diamine, the growth of strain CE3 was i) halted on RMM-Gln or RMMGlu; ii) slightly reduced on RMM-His; and iii) not appreciably affected on either TYR or RMM with Glc, Suc, or Asn as C source. Finally, $1 \mathrm{mM}$ diamide completely blocked the growth capacity of strain CE3 in all the assayed media, including TYR (Fig. 3D). As expected, gshB and gor mutants were more susceptible to diamide treatment than its wild-type parent (Fig. 3D). For instance, the ability of the $g s h B$ mutant to grow in RMM was already abolished at $50 \mu \mathrm{M}$ diamide (Fig. 3D). Surprisingly, the complemented mutant, strain CTGUT43 $\left(g s h B^{-/+}\right)$, was more resistant to diamide than strain CE3. For instance, at $1 \mathrm{mM}$ diamide, the growth ability of strain CTGUT43 $\left(\mathrm{gshB}^{-/+}\right)$ on TYR, RMM-Suc, or RMM-Asn was reduced but not blocked, as observed with strain CE3.

\section{Gln as N source.}

Rhizobium spp. require Aap and Bra permeases to grow with Gln as C source but not to grow with Gln as N source (Hosie et al. 2002; Taté et al. 2004). We speculated that, if GSH is essential to achieve maximal levels of Gln uptake activity through Aap and Bra (Figs. 1 and 3), gshB and gor should be dispensable for Gln utilization as $\mathrm{N}$ source. To verify this assumption, $R$. etli strains were plated on RMM-Glc with different $\mathrm{N}$ sources (Fig. 4A). Notably, whereas $g s h B$ was essential, the gor, aapM, and $g d h B$ genes were dispensable to use Gln (or Glu) efficiently as N source, even at a concentration of $50 \mu \mathrm{M}$ to $5 \mathrm{mM}$. Conversely, all strains assayed grew with His or $\mathrm{NH}_{4}{ }^{+}$as $\mathrm{N}$ source. Certainly, the $g s h B$ mutant could utilize 
Gln as N source when transformed with plasmid pAR367 (Fig. 4A) or when exogenous GSH $(100 \mu \mathrm{M})$ was supplied (data not shown). With Gln as N source, the growth of the $g \operatorname{sh} B$ mutant was delayed but not blocked, because bacterial growth began to be perceptible 4 to 5 days postplating (data not shown). Furthermore, the $g s h B$ mutant, like strains CE3, CTGUT15( gor $\left.^{-}\right)$, CTGUT14 $\left(\right.$ aapM $\left.^{-}\right)$, and CTGUT27 $\left(\right.$braD $\left.^{-}\right)$, grew on RMMGlc with $1 \mathrm{mM}$ Glu-Glu dipeptide as sole N source. Thus, Aap and Bra systems are dispensable for Glu-Glu or His uptake and, most remarkably, the gshB mutant is able to grow using alternative sources of intracellular Glu, such as His or GluGlu. Conversely, the wild-type strain of $R$. etli was unable to grow with Glu-Glu dipeptide as sole source of $\mathrm{C}$ and $\mathrm{N}$.

The influence of GSH on the use of Gln or Glu as N source was also evaluated by analyzing a glutamate synthase (GOGAT) mutant of $R$. etli, strain CTNUX10 $\left(g l t D^{-}\right)$(Ferraioli

A
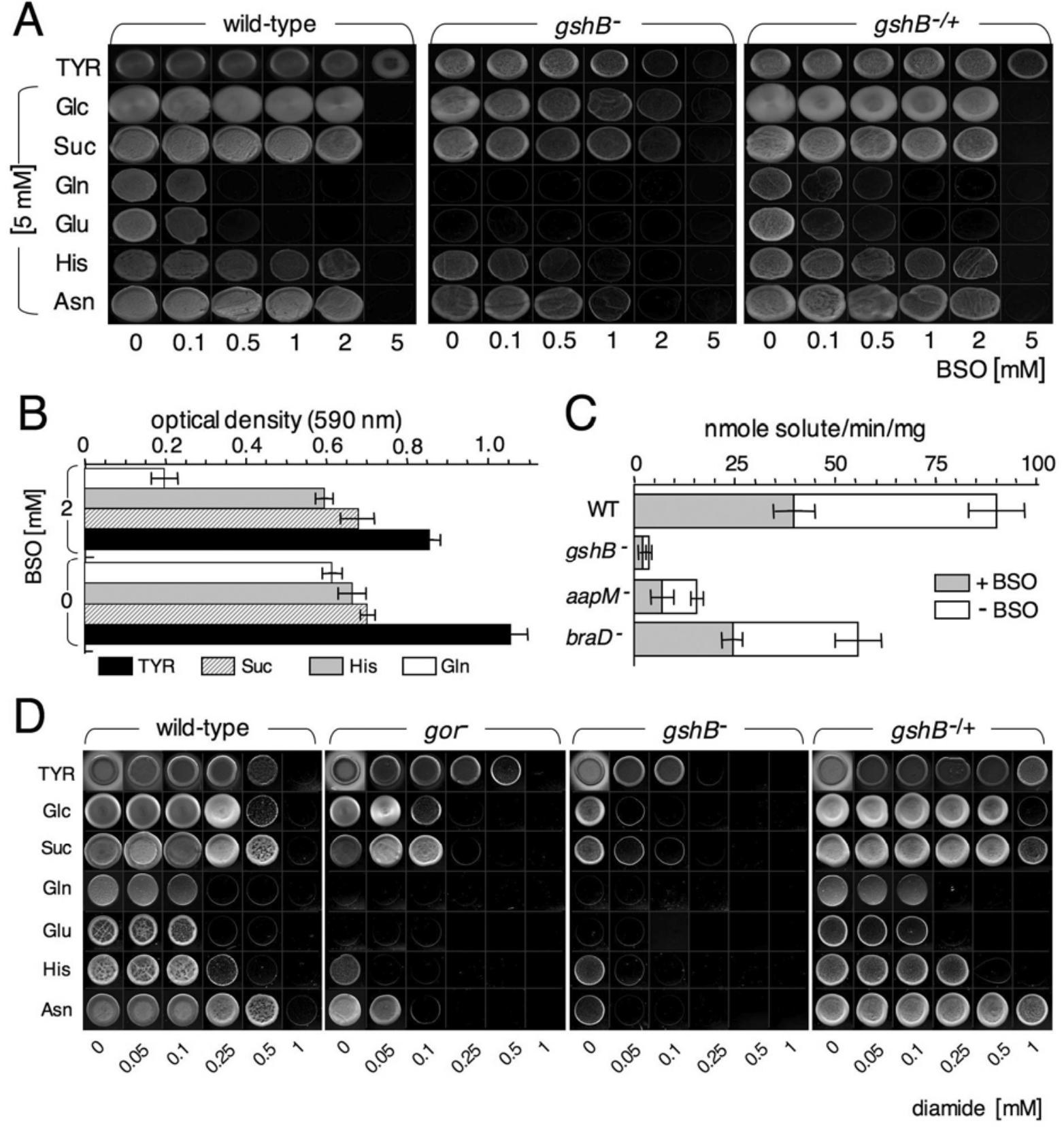

Fig. 3. Effect of L-buthionine(S,R)-sulfoximine (BSO) and diamide on glutamine (Gln) utilization ability of Rhizobium etli. A, Effect of BSO on the bacterial ability to grow on solid medium. Cells $\left(10^{4}\right.$ in $5 \mu$ l) of strains CE3(WT), CTGUT43 $\left(g s h B^{-}\right)$, and CTGUT43-pAR367 $\left(g s h B^{-/+}\right)$, indicated at the top, were spotted on TYR or rhizobia minimal medium (RMM) supplemented with $5 \mathrm{mM}$ glucose (Glc), succinate (Suc), Gln, Glu, histidine (His), or asparagine (Asn), indicated to the left. BSO was added at the indicated concentration (bottom). Bacterial colonies (3 days postinoculation [dpi] at $30^{\circ} \mathrm{C}$ ) are shown. $\mathbf{B}$, Effect of BSO on the R. etli ability to grow in liquid medium. Strain CE3 was inoculated (initial optical density at $590 \mathrm{~nm}\left[\mathrm{OD}_{590}\right]=0.05$ ) on liquid media TYR (black bars) or RMM supplied with Gln (white bars), Suc (dashed bars), or His (gray bars), with or without BSO addition (2 mM) (left). Values of culture turbidity measured after incubation $\left(24 \mathrm{~h}\right.$ at $\left.30^{\circ} \mathrm{C}\right)$ are shown. Data represent the means of three different experiments. Standard deviations (SDs) are indicated by error bars. C, Effect of BSO on Gln uptake activity. $R$. etli strains (left) was grown in TYR plus $2 \mathrm{mM} \mathrm{BSO}$ (inoculated at OD $_{590}=0.01$, harvested at $\left.\mathrm{OD}_{590}=0.6\right)$ and shifted $\left(\mathrm{OD}_{590}=0.3\right)$ to either RMM-Gln alone (white bars) or supplemented with BSO ( $2 \mathrm{mM}$; black bars). After incubation $\left(2 \mathrm{~h}\right.$ at $\left.30^{\circ} \mathrm{C}\right)$, the cells were harvested and Gln uptake capacity was measured. Data represent the means of three experiments. SDs are indicated by error bars. D, Effect of diamide on the bacterial ability to grow on solid medium. Cells $\left(10^{4}\right.$ in $\left.5 \mu \mathrm{l}\right)$ of strains CE3(WT), CTGUT15(gor $\left.{ }^{-}\right)$, CTGUT43(gshB $\left.B^{-}\right)$, and CTGUT43-pAR367 $\left(\mathrm{gsh}^{-/+}\right)$, indicated to the top, were spotted on TYR or RMM supplemented with $5 \mathrm{mM}$ Glc, Suc, Gln, Glu, His, or Asn, indicated to the left. Diamide was added at the concentration indicated (bottom). Bacterial colonies ( 3 dpi at $30^{\circ} \mathrm{C}$ ) are shown. 
et al. 2002). In Rhizobium spp., GOGAT is essential for $\mathrm{NH}_{4}{ }^{+}$ assimilation (Patriarca et al. 2002). As expected, strain CTNUX10 $\left(\mathrm{glt} \mathrm{D}^{-}\right)$grew on $\mathrm{RMM}-\mathrm{Glc} / \mathrm{NH}_{4}{ }^{+}$(or RMMSuc/ $\mathrm{NH}_{4}^{+}$) only when Glu or a source of Glu (namely Gln, Asn, or His) was available (Fig. 4B). The ability of Gln to overcome the Glu auxotrophy of strain CTNUX10 $\left(\mathrm{gltD}^{-}\right)$was prevented by BSO $(500 \mu \mathrm{M})$. Conversely, BSO could not prevent the growth rescue induced by the other intracellular sources of Glu (i.e., Asn and His) (Fig. 4B).

\section{Gln interfere with the growth of the gsh $B$ mutant.}

The growth of the $g s h B$ mutant was prevented when $5 \mathrm{mM}$ Gln (or Glu) was added to RMM containing either Glc, Suc, His, or Asn as an alternative C source (Fig. 4C). The Glninduced inhibitory effect could be avoided either by adding GSH $(100 \mu \mathrm{M})$ (Fig. 4C) or by transforming the mutant with plasmid pAR367 (Fig 4D). Remarkably, Gln strongly delayed (colony formation began to be evident 5 to 6 days postinoculation [dpi]) but did not block the growth of strain CTGUT43 $\left(g s h B^{-}\right)$. Unexpectedly, the lowest concentration of Gln (50 $\mu \mathrm{M})$ capable of inhibiting the growth of the $g s h B$ mutant corresponds to the minimal concentration required to rescue the auxotrophy of the gltD mutant (lacking GOGAT) (Fig. 4D). Furthermore, Gln was unable to influence markedly the growth of gor, aap $M$, and gdhB mutants, independently from the concentration used. Finally, as a control, the $g s h B$ mutant grew on RMM-Glc/ $\mathrm{NH}_{4}{ }^{+}$supplemented with $5 \mathrm{mM}$ His (Fig. 4D) or Glu-Glu dipeptide (not shown). These data support the occurrence of a specific mechanism of growth interference induced by Gln or Glu in a $g s h B$ background.

\section{The symbiotic behavior of the gshB mutant.}

In order to assess the nodulation capacity of the gshB mutant, P. vulgaris seedlings were inoculated with Rhizobium bacteria and, 3 weeks later, the nodules developed on the primary root of the plants were counted and examined. Strain CTGUT43 $\left(g s h B^{-}\right)$ induced up to 3 nodules per plant, whereas strain CE3 induced, on average, approximately 15 nodules per plant (Fig. 5A). Moreover, 21-day-old nodules induced by the gshB mutant were highly heterogeneous in size, frequently reaching a notable dimension (fresh weight up to twofold higher), and displayed a substantially lower (approximately fivefold) acetylene reduction activity (ARA) compared with normal (CE3-induced) nodules (Fig. 5A). It is worth noting that strain CTGUT43(gshB-) was reisolated from $100 \%$ of the few nodules induced. In contrast, on the secondary and tertiary roots, the $g s h B$ mutant induced a higher (up to threefold) number of nodules compared with the wild-type strain (data not shown). This delayed nodulation was
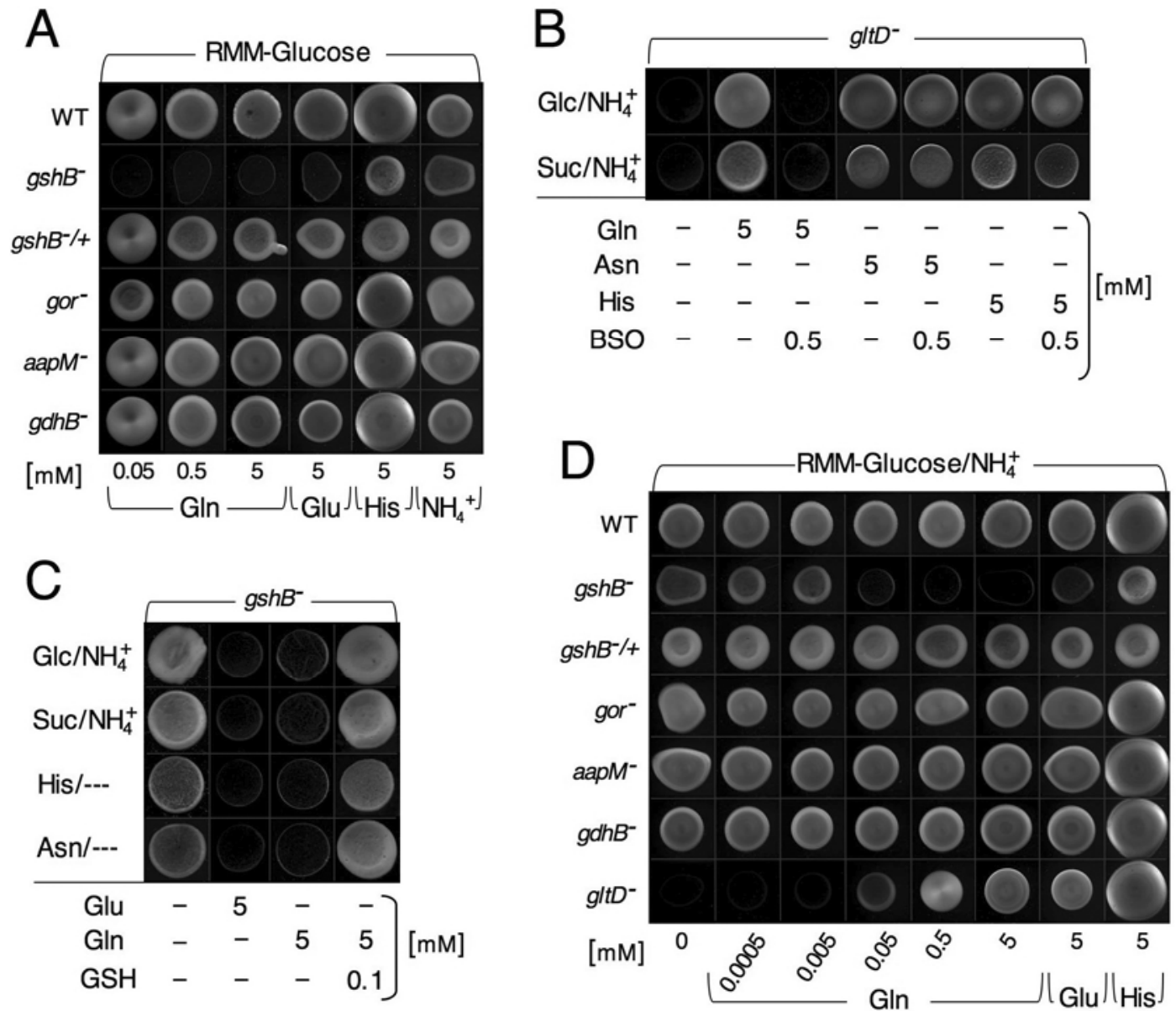

Fig. 4. Effect of glutamine (Gln) on the growth of Rhizobium etli mutants. A, Gln as N source. Cells (10 ${ }^{4}$ in $\left.5 \mu l\right)$ of strains CE3(WT), CTGUT43( $g$ sh $\left.B^{-}\right)$, CTGUT43-pAR367 $\left(\mathrm{gsh}^{-/+}\right)$, CTGUT15 $\left(\mathrm{gor}^{-}\right)$, CTGUT14 $\left(\right.$aapM $\left.^{-}\right)$, and CTGUT3 $\left(\mathrm{gdhB}^{-}\right)$, indicated to the left, were spotted on rhizobia minimal medium (RMM)-glucose (Glc) containing, as $\mathrm{N}$ source Gln, Glu, histidine (His), or ammonium $\left(\mathrm{NH}_{4}^{+}\right)$, as indicated (bottom). Concentration used is indicated at the bottom. B, Effect of L-buthionine $(S, R)$-sulfoximine (BSO) on the growth of strain CTNUX10 $\left(\mathrm{glt}^{-}\right)$. Cells were spotted (10 4 in $\left.5 \mu \mathrm{l}\right)$ onto RMM agar containing $\mathrm{NH}_{4} \mathrm{Cl}$ as $\mathrm{N}$ source and either Glc or succinate (Suc) as C source; $5 \mathrm{mM}$ Gln, His, or asparagine (Asn) (left) was added to specific plates. A subgroup of plates was also supplemented with BSO. C, Effect of Gln on the gshB mutant growth. Strain CTGUT43(gshB $\left.{ }^{-}\right)$was spotted onto RMM agar supplemented with either His or Asn $(5 \mathrm{mM})$ as $\mathrm{C}$ and $\mathrm{N}$ source or onto $\mathrm{RMM}$ agar containing either $5 \mathrm{mM} \mathrm{Glc}$ or $5 \mathrm{mM}$ Suc plus $\mathrm{NH} \mathrm{Cl}_{4}$ as $\mathrm{C}$ and $\mathrm{N}$ source, respectively (left). To a group of plates, $100 \mu \mathrm{M}$ glutathione (GSH) was added (bottom). D, Gln concentration and bacterial growth. Strains (left) were spotted on $\mathrm{RMM-Glc} / \mathrm{NH}_{4}{ }^{+}$supplemented with either Gln, Glu, or His as indicated (bottom). Colonies are shown at 3 days postinoculation and $30^{\circ} \mathrm{C}$. 
characterized by the formation of undeveloped and ineffective nodules, resembling the nodules induced by the $g s h B$ mutant of $R$. tropici on the roots of common bean (Muglia et al. 2008). As expected, the nodulation ability of strain CTGUT43 $\left(g s h B^{-}\right)$was improved by watering the inoculated plants with Jensen medium supplemented with $100 \mu \mathrm{M}$ GSH (Fig. 5A). Furthermore, strain CTGUT43 $\left(g s h B^{-/+}\right)$induced an almost normal number (approximately 12 per plant) of efficient $\left(\mathrm{ARA}^{+}\right)$nodules. The competitiveness of the $g s h B$ mutant was evaluated as previously described (Taté et al. 1997), inoculating the roots of 24 seedlings of common bean with a mixture (1:1 ratio) of strain CTGUT43 $\left(g s h B^{-}\right)$and CE3. The $g s h B$ mutant was able to invade approximately $0.5 \%$ of the nodules $(21 \mathrm{dpi})$ located on the primary roots (192 nodules tested).

The 21-day-old nodules induced by strains CE3 and CTGUT43 $\left(g s h B^{-}\right)$show a similar tissue organization (Fig. 5B). However, the invaded cells (ICs) located at the periphery of the central tissue were less regular in CTGUT43 $\left(g s h B^{-}\right)$-induced nodules than in normal nodules, with some ICs showing a heterogeneous staining and abnormal symbiosomes (Fig. 5B). Moreover, the uninvaded cells of CTGUT43 $\left(g s h B^{-}\right)$-induced nodules contained prominent starch grains. As previously shown (Cermola et al. 2000; Ferraioli et al. 2002), these features are indicators of premature senescence. Finally, the plants nodulated by the $g s h B$ mutant developed sclerotic leaves, a symptom of nitrogen deficiency (Fig. 5C). This phenotype was as severe as that observed in plants inoculated with two different $\mathrm{Fix}^{-}$(unable to fix nitrogen) mutant strains of $R$. etli; namely, CFNX247(nifA ${ }^{-}$) and $\mathrm{CFNX249(nifH1^{- } / \text { nifH2 }}{ }^{-}$). Hence, as in the case of other rhizobia, a normal GSH metabolism is essential for the symbiotic efficiency of $R$. etli.

\section{DISCUSSION}

Here, we have described the identification of a previously unforeseen role of GSH in bacteria. Briefly, an efficient process of GSH synthesis or reduction is essential to allow the growth of $R$. etli with or in the presence of Gln. In a series of experiments, we have demonstrated that, among the few steps required for Gln utilization or catabolism, only the process of Gln transport (uptake) depends strictly on GSH homeostasis (Fig. 1). More than $70 \%$ of the total Gln uptake capacity of $R$. etli depends on Aap permease and, accordingly, only a functioning Aap system guaranteed the use of Gln as sole $\mathrm{C}$ and $\mathrm{N}$ source. Remarkably, the Gln transport capacity of gshB, gor, and aapM mutants was similarly reduced, allowing us to conclude that the Gln uptake capacity of the GSH-deficient mutants ( $g s h B$ and gor) is inadequate to permit their growth with Gln (or Glu) as sole source of C and N.

The requirement of GSH for Gln utilization was supported by the results obtained assaying the effect of BSO and diamide (Fig. 3). In fact, when supplied at appropriate sublethal concentrations, these chemicals alone were sufficient to mimic the effect of either a $g s h B$ or gor mutation. Moreover, exogenously added GSH was sufficient to overcome the growth inhibition induced by BSO or diamide, thus indicating that they reduced the bacterial capacity to utilize Gln (or Glu) only by affecting the GSH homeostasis. Remarkably, BSO induced a substantial reduction of Gln uptake activity in all strains assayed, including the gshB mutant, thus supporting genetic evidence indicating that GSH influences, in a positive manner, the process of Gln uptake, and excluding a negative role of $\gamma$ Glu-Cys in this process. Notably, BSO at a high concentration prevents the growth of the wild-type strain of $R$. etli in all media assayed, including minimal medium, thus suggesting that $R$. etli strictly depends on GSH or $\gamma$ GluCys to grow. Moreover, considering that i) BSO mimics the effect of a $g s h A$ mutation and ii) Glndeficient mutants were identified by replica plating of bacteria in minimal medium, it is not surprising that a $g s h A$ mutant (i.e., a strain completely defective in both $\gamma$ GluCys and GSH and, hence, unable to grow in minimal medium) was not isolated from the screening performed.

Even though the role of GSH in Gln catabolism remains to be defined, its positive influence on the Gln uptake activity

A

B

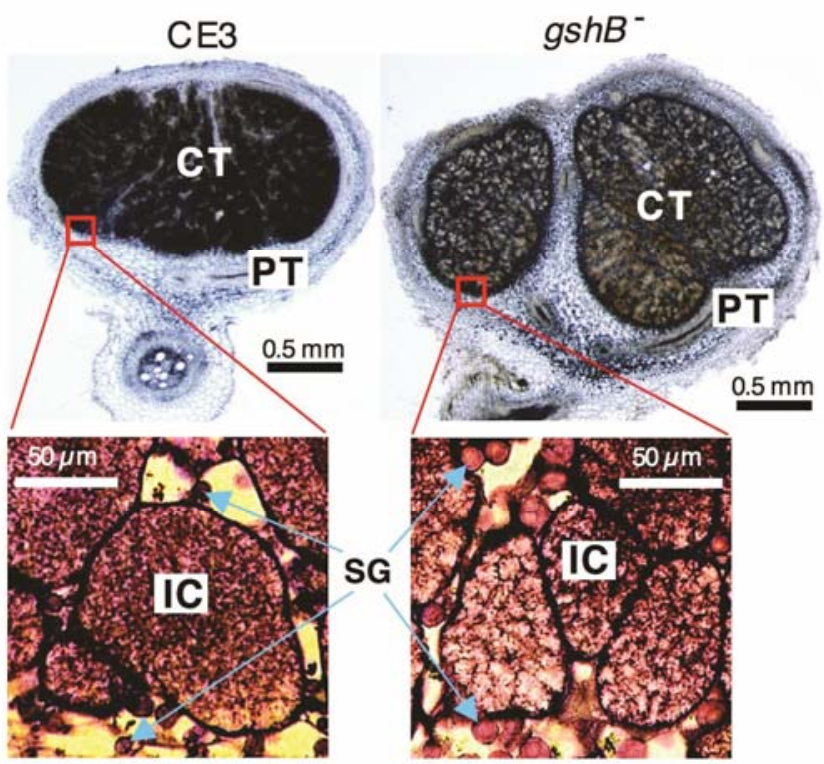

Fig. 5. Symbiotic behavior of Rhizobium etli mutants. A, Germinated seedlings of Phaseolus vulgaris were inoculated with the indicated strains (left) and, 21 days postinoculation (dpi), the number, fresh weight, and acetylene reduction activity (ARA) of the nodules developed on the main roots were determined. Numbers are the means and standard deviations of data obtained from three experiments. In a single experiment, the main root of 60 plants was inoculated with each bacterial strain. B, Upper: photographs of nodules elicited by strain CTGUT43( $\left.g s h B^{-}\right)$and CE3(WT). Central tissue (CT) and peripheral tissue (PT) are indicated. Lower: photographs of representative invaded cells (ICs). Starch granules (SG) located in the uninvaded cells are indicated (blue arrows). C, Leaves of $P$. vulgaris plants nodulated by $R$. etli mutants. Strains inoculated were CE3(WT), CFNX247(nifA ${ }^{-}$), CFNX249(nifH1 ${ }^{-} /$nifH $\left.2^{-}\right)$, or CTGUT43 $\left(g s h B^{-}\right)$, as indicated. The central one of the first triplet of leaves developed in each symbiotic pair was harvested (21 dpi) and photographed. 
may be considered as a metabolic paradox. In fact, because the Gln degradation product Glu is a precursor of GSH synthesis, a negative feedback regulation (i.e., low GSH levels $\rightarrow$ high Gln uptake activity) could be expected. However, GSH is required for Glu transport in some eukaryotic cell lines (Agostinho et al. 1997). Moreover, in both yeast and some mammalian cell lines, a direct role of GSH in amino acid transport, through a complex cycling process named the $\gamma$-glutamyl cycle, has been demonstrated (Griffith et al. 1978). The presence in R. etli of a similar GSH-dependent cycle, essential for Gln uptake, remains to be established, even though it recently has been shown that, in Helicobacter pylori, the $\gamma$-glutamyl transpeptidase, a key enzyme in the $\gamma$-glutamyl cycle, is expressed and exhibited Gln hydrolysis activity (Shibayama et al. 2007).

Surprisingly, we observed that Gln significantly delayed the growth of GshB-knockout bacteria even when plated in the presence of alternative sources of $\mathrm{C}$ and $\mathrm{N}$. Overall, our data suggest that i) Gln should be metabolized (transported and degraded) to interfere with bacterial growth and ii) GOGAT activity is required to avoid growth inhibition induced by Gln of GSH-deficient (BSO-treated) bacteria (Fig. 4). Certainly, exogenously adding Gln (or Glu) by inducing the Aap/Gdh pathway (for uptake or catabolism) may reduce the amount of Glu available to be funneled into the GSH synthesis pathway; this, in turn, should be compensated for by inducing GOGAT enzyme (Glu synthesis) (Fig. 2). In correlation, after shifting the cells into RMM-Gln, GOGAT activity was twofold higher in the $g s h B$ mutant than in its wild-type parent (our unpublished results). Therefore, in the presence of exogenous Gln and in the absence of GSH synthesis, a futile cycle (Glu synthesis and degradation operating simultaneously) may be generated which slows down the bacterial growth. It is worth noting that evidence for a fine regulated Gln cycle has been previously obtained in Neurospora crassa (Mora 1990), S. meliloti, and $R$. etli (Encarnacion et al. 1998), even if a putative role of GSH in its regulation was never hypothesized.

The symbiotic performance of the $g s h B$ mutant was altered at different levels of nodule formation, function, and maintenance (Fig. 5). A low number of nodules may be due to a reduced invasion capacity and using green fluorescent protein-labeled bacteria (Sartorius et al. 2009). We have observed that most of the initial invasion events (i.e., the development of infection threads) induced by the $g s h B$ mutant on the main root of inoculated plants undergo early abortion (our unpublished observations). Moreover, similar to the $R$. tropici gshB mutant (Riccilo et al. 2000), the $R$. etli gshB mutant was unable to compete efficiently for nodulation with its wild-type parent. During plant invasion, Rhizobium bacteria should adapt their metabolism to the microenvironment generated by the host partner and, hence, GSHdeficient bacteria should be susceptible to these chemical and physical challenges. However, because aapM and braD mutants of $R$. etli, which are defective in Gln transport or utilization, are able to induce a normal number of nodules on the main root of $P$. vulgaris, the nodulation inefficiency of the $g s h B$ mutant should not be due to its inability to uptake or utilize Gln. On the other hand, the reduced nitrogenase activity displayed by the few nodules induced by the mutant may be dependent on a reduced functionality of the Gln transporters in the GSH-deficient bacteroids. In fact, Aap and Bra systems are key players of a mechanism of amino-acid cycling involving Gln or Glu and essential for an efficient symbiotic interaction (Lodwig et al. 2003). A putative key role of GSH in the regulation of this amino-acid cycling in bacteroids should be further investigated. Finally, as in $R$. tropici and S. meliloti (Harrison et al. 2005; Muglia et al. 2008), nodules elicited by the $g s h B$ mutant of $R$. etli on the main root of $P$. vulgaris exhibit clear-cut signs of early senescence. However, a similar phenotype was also ob- served in ineffective nodules elicited by $\mathrm{Fix}^{-}$mutant strains of $R$. etli (Cermola et al. 2000). Thus, the lack of bacterial GSH production could adversely influence the nodule maintenance, directly or indirectly reducing the expression or the activity of the nitrogenase complex.

\section{MATERIALS AND METHODS}

Bacterial strains and growth media.

R. etli strains (Table 1) CE3 (wild-type), CTGUT3 $\left(g d h B^{-}\right)$, CTGUT14(aapM $\left.{ }^{-}\right)$, CTGUT15( gor $\left.^{-}\right)$, CTGUT27 $\left(\right.$braD $\left.^{-}\right)$, CTNUX10 $\left(\right.$ gltD $\left.^{-}\right)$, CFNX247(nifA $\left.{ }^{-}\right)$, and CFNX249 (nifH1 ${ }^{-}$ /nifH2 $2^{-}$) described elsewhere (Brito et al. 1997; Ferraioli et al. 2002; Girard et al. 1996; Taté et al. 2004) were grown at $30^{\circ} \mathrm{C}$ with shaking in complete medium TYR or in a chemically defined RMM as described elsewhere (Taté et al. 1997). E. coli strain DH5 $\alpha$ was grown at $37^{\circ} \mathrm{C}$ with shaking in TY medium. All media were solidified with $1.5 \%$ agar (wt/vol) (Difco Laboratories, Detroit). Antibiotics were added to the media in the following final concentrations: tetracycline at $15 \mu \mathrm{g} / \mathrm{ml}$ for E. coli and $5 \mu \mathrm{g} / \mathrm{ml}$ for $R$. etli, ampicillin at $20 \mu \mathrm{g} / \mathrm{ml}$, nalidixic acid at $20 \mu \mathrm{g} / \mathrm{ml}$, and kanamycin at $50 \mu \mathrm{g} / \mathrm{ml}$ for $R$. etli. Antibiotics and Glu-Glu dipeptide (G3640) were purchased from Sigma-Aldrich (St. Louis). To test the bacterial growth phenotype on RMM solid media, $R$. etli strains were grown in liquid TYR to exponential growth phase and harvested by centrifugation $\left(2,500 \times g\right.$ for $10 \mathrm{~min}$ at $\left.4^{\circ} \mathrm{C}\right)$. The bacterial pellet was washed twice with sterile RMM and resuspended at the required density in RMM without added $\mathrm{C}$ and $\mathrm{N}$ sources.

\section{Tn5 mutagenesis.}

Transposon mutagenesis of $R$. etli was carried out as previously described (Taté et al. 1997). For the ampicillin-mediated enrichment procedure, a suspension of approximately $10^{5}$ kanamycin-resistant transconjugants was used to inoculate RMM supplemented with Gln $(5 \mathrm{mM})$ plus ampicillin $(20 \mu \mathrm{g} / \mathrm{ml})$. Bacteria were incubated for 2 days at $30^{\circ} \mathrm{C}$, with two changes of the medium every day, and then poured on TYR supplemented with kanamycin $(50 \mu \mathrm{g} / \mathrm{ml})$. Auxotrophs were excluded by replica plating of the resulting kanamycin-resistant colonies (approximately 200) on minimal medium (RMM) containing Glc or Suc as $\mathrm{C}$ source and $\mathrm{NH}_{4} \mathrm{Cl}$ as $\mathrm{N}$ source. Four mutant strains unable to grow with Gln but able to grow with Glc or Suc as sole source of $\mathrm{C}$ were isolated and characterized.

\section{DNA manipulation.}

To clone the Tn5-flanking DNA regions, digestion of total DNA (500 ng) was performed with EcoRI followed by ligation to EcoRI-digested pGEM7Zf+ (Promega Corp., Madison, WI, U.S.A.). After transformation of $E$. coli DH5 $\alpha$, kanamycin-resistant colonies were isolated. In the case of strain CTGUT43, a DNA fragment $(12 \mathrm{~kb})$ carrying the Tn5- and genomic DNAflanking regions was cloned (plasmid pAR363); plasmid DNA was purified and the nucleotide sequence was established using a standard Tn5 outward-reading primer 5'-GAAAGGTTCCG TTCAGGACGCTAC- $3^{\prime}$ and appropriate oligonucleotides. The $g s h B$ gene was PCR amplified using the following oligonucleotides: $g s h B f$ 5'-CGGAATTCGAAGCCTTTGGCAATCG CCTA-3' and $g s h B r$ 5'-GCTCTAGACCTTCTATGCCCTGGA ATG-3' as primers (restriction sites for EcoRI and XbaI are underlined) and total DNA, isolated from strain CE3, as a template. The amplified DNA fragment $(1,323 \mathrm{bp})$ was digested with EcoRI and XbaI, and ligated with plasmid pMP220 (Spaink et al. 1987) digested with the same restriction enzymes. The resulting plasmid, pAR367, was used to transform strain CTGUT43 by electroporation as previously described (Taté et al. 1997). 
GIn transport assays and $\mathrm{CO}_{2}$ production from Gln.

An uptake assay was performed by a rapid-filtration method as described elsewhere (Taté et al. 1998). Briefly, bacteria were grown in $\mathrm{TYR}$ at $30^{\circ} \mathrm{C}$ under aeration up to an optical density at $590 \mathrm{~nm}\left(\mathrm{OD}_{590}\right)$ of 0.6 and harvested by centrifugation $\left(2,500 \times g\right.$ for $10 \mathrm{~min}$ at $\left.4^{\circ} \mathrm{C}\right)$. The bacterial pellet was washed twice with sterile water and resuspended $\left(\mathrm{OD}_{590}\right.$ of $0.3)$ in either RMM-Gln (5 mM), RMM-Suc/ $\mathrm{NH}_{4} \mathrm{Cl}(5 \mathrm{mM}$ each), or $\mathrm{RMM}-\mathrm{Glc} / \mathrm{NH}_{4} \mathrm{Cl}(5 \mathrm{mM}$ each); incubated $(2 \mathrm{~h}$ at $\left.30^{\circ} \mathrm{C}\right)$ under aeration; and harvested by centrifugation $(2,500 \times$ $g$ for $10 \mathrm{~min}$ at $4^{\circ} \mathrm{C}$ ). The bacterial pellets were washed twice with sterile water and suspended in RMM. Before filtration, Gln $(30 \mu \mathrm{M}$ final concentration $)$ and $\mathrm{L}_{-}\left[\mathrm{U}_{-}{ }^{14} \mathrm{C}\right] \mathrm{Gln}(50 \mu \mathrm{Ci} / \mathrm{ml}$, $244 \mu \mathrm{Ci} / \mathrm{mmol})(10 \mu \mathrm{M}$ final concentration) was added.

Gln respiration was measured as previously described (Taté et al. 2004). Bacteria were grown as for Gln transport and resuspended in $0.2 \mathrm{ml}\left(\mathrm{OD}_{590}\right.$ value of 3.0) of RMM-Gln $(40 \mu \mathrm{M}$ final concentration). After addition of $10 \mu \mathrm{l}$ ( 2 nmoles $)$ of a labeled L-[U- $\left.{ }^{14} \mathrm{C}\right] \mathrm{Gln}$ solution $(50 \mu \mathrm{Ci} / \mathrm{ml}, 244 \mu \mathrm{Ci} / \mathrm{mmol})$, the mixture was incubated $\left(15 \mathrm{~min}, 30^{\circ} \mathrm{C}\right)$ and the reaction was stopped by addition of cold Gln (50 mM final concentration) plus $1 \mathrm{ml}$ of $0.9 \mathrm{M} \mathrm{HClO}_{4}$. The ${ }^{14} \mathrm{CO}_{2}$ liberated from this acid mixture was captured in a $\mathrm{CO}_{2}$ trap (appended from the cap) containing $1 \mathrm{M}$ benzethonium hydroxide (Sigma-Aldrich) in $\mathrm{CH}_{3} \mathrm{OH}$. After $3 \mathrm{~h}$ of incubation, the trap was removed and its contents were diluted in $50 \%$ scintillation mix (Ultima Gold; PerkinElmer, Foster, CA, U.S.A.) and counted ( $\beta$-Counter, Beckman Coulter, Fullerton, CA, U.S.A.). The protein content of the bacterial suspension was determined with the Bio-Rad kit.

\section{Glutamate dehydrogenase activity.}

$R$. etli strains grown in TYR were harvested by centrifugation $(2,500 \times g)$, washed, and resuspended in RMM-Gln $\left(\mathrm{OD}_{590}\right.$ of 0.3$)$. Cells were incubated $\left(2 \mathrm{~h}\right.$ at $\left.30^{\circ} \mathrm{C}\right)$, harvested, resuspended in extraction buffer (20 mM HEPES pH 8.5, 100 $\mathrm{mM} \mathrm{NaCl}$, and $1 \mathrm{mM}$ EDTA), and disrupted by sonic oscillation at $0^{\circ} \mathrm{C}$. Cellular debris were removed by centrifugation $\left(27,000 \times g\right.$ for $20 \mathrm{~min}$ at $\left.4^{\circ} \mathrm{C}\right)$ and, with the resulting crude extracts used as a source of Gdh, the initial rate of glutamatedependent NADH appearance was measured by monitoring the absorbance at $340 \mathrm{~nm}$ (initial rates of NADH formation) in 2 $\mathrm{ml}$ of a reaction mixture containing $100 \mathrm{mM}$ HEPES buffer (pH 8.5), $50 \mathrm{mM}$ L-glutamate, and $2.5 \mathrm{mM}$ NAD. The rates were corrected for the production of NADH in the absence of added glutamate.

\section{Nodulation test.}

Seed of $P$. vulgaris 'Negro Jamapa' were surface sterilized with $5 \% \mathrm{H}_{2} \mathrm{O}_{2}$ for $30 \mathrm{~min}$, washed with sterile water, and germinated at $23^{\circ} \mathrm{C}$ for $72 \mathrm{~h}$ on a petri dish (1\% water agar). The main root of germinated seed was inoculated with $100 \mu \mathrm{l}$ of a bacterial suspension $\left(10^{6}\right.$ cells $\left./ \mathrm{ml}\right)$ in $50 \mathrm{mM}$ phosphate buffer ( $\mathrm{pH}$ 7.0). Plants were cultured in a growth chamber maintained at 70 to $75 \%$ relative humidity at $23^{\circ} \mathrm{C}$ in light and $19^{\circ} \mathrm{C}$ in darkness, with a 16-h-daylight period, using an $\mathrm{N}$-free medium (Taté et al. 1998). To test the nodule occupancy, nodules located in the primary root were surface sterilized (5\% sodium hypochlorite for $1 \mathrm{~min}, 70 \%$ ethanol for $1 \mathrm{~min}$, and two rinses with sterile water) and crushed in 96-multiwell plates $(100 \mu \mathrm{l}$ of RMM per well). Cell suspensions were then streaked (using toothpicks) on plates of TYR agar supplemented with nalidixic acid $(20 \mu \mathrm{g} / \mathrm{ml})$ or with nalidixic acid $(20 \mu \mathrm{g} / \mathrm{ml})$ plus kanamy$\operatorname{cin}(50 \mu \mathrm{g} / \mathrm{ml})$. Aliquots were also streaked on RMM-Gln and RMM-His. A nodule was considered invaded by strain CTGUT43 $\left(g s h B^{-}\right)$when only $\mathrm{Gln}^{-}$, $\mathrm{His}^{+}$kanamycin-resistant bacteria were isolated from that nodule. For the measurement of ARA of nodulated roots, plants were harvested and the root system was immediately detached and incubated at $25^{\circ} \mathrm{C}$ in $15-\mathrm{ml}$ rubber-cap tubes containing $1 / 10(\mathrm{vol} / \mathrm{vol})$ acetylene. The ethylene produced at different time points was quantified with a Sigma 3B gas chromatograph (Perkin-Elmer, Foster, CA, U.S.A.) equipped with a Porapak T column.

\section{Optical microscopy.}

For histological analysis, 21-day-old nodules were excised from the primary root with a razor blade and fixed in a $50 \mathrm{mM}$ potassium phosphate buffer $(\mathrm{pH} 7.4)$ containing $4 \%$ paraformaldehyde, $3 \%$ glutaraldehyde, and $4 \%$ sucrose. To observe nodule tissues, samples were embedded in agarose $(4 \%$ [wt/vol]) sections $(70 \mu \mathrm{m})$ were obtained using a Leica vibrating-blade microtome (model VT1000S; Leica, Nussloch, Germany) and observed with a Leica microscope (model MZ16FA; Leica Microsystems, Wetzlar, Germany). Digital images were captured with a video camera (Leica DFC320). To observe the invaded cells, nodule samples were rinsed, dehydrated, and embedded in Poly/Bed 812 resin (Polyscience, Warrington, PA, U.S.A.) as previously described (Taté et al. 2004). Semithin sections ( $2 \mu \mathrm{m}$ thick), obtained with a Leica microtome equipped with a diamond knife (Diatome, Biel, Switzerland), were stained with toluidine blue $(0.04 \%$ in distilled water) and observed.

\section{ACKNOWLEDGMENTS}

This work was supported by grants from the Ministero Istruzione Universitá Ricerca-Fondo Investimenti Ricerca Base project RBNE01KZE7. We thank L. Girard for the gift of Fix ${ }^{-}$strains of $R$. etli, M. Iaccarino for useful discussion, and A. M. Aliperti for help with the manuscript.

\section{LITERATURE CITED}

Agostinho, P., Duarte, C. B., and Oliveira, C. R. 1997. Impairment of excitatory amino acid transporter activity by oxidative stress conditions in retinal cells: Effect of antioxidants. FASEB (Fed. Am. Soc. Exp. Biol.) J. 11:154-163.

Brito, B., Martinez, M., Fernandez, D., Rey, L., Cabrera, E., Palacios, J. M., Imperial, J., and Ruiz-Argueso, T. 1997. Hydrogenase genes from Rhizobium leguminosarum bv. viciae are controlled by the nitrogen fixation regulatory protein nifA. Proc. Natl. Acad. Sci. U.S.A. 94:60196024.

Cermola, M., Fedorova, E., Taté, R., Riccio, A., Favre, R., and Patriarca, E. J. 2000. Nodule invasion and symbiosome differentiation during Rhizobium etli-Phaseolus vulgaris symbiosis. Mol. Plant-Microbe Interact. 13:733-741

Encarnacion, S., Calderon, J., Gelbard, A. S., Cooper, A. J., and Mora, J. 1998. Glutamine biosynthesis and the utilization of succinate and glutamine by Rhizobium etli and Sinorhizobium meliloti. Microbiology 144:2629-2638.

Ferraioli, S., Taté, R., Cermola, M., Favre, R., Iaccarino, M., and Patriarca, E. J. 2002. Auxotrophic mutant strains of Rhizobium etli reveal new nodule development phenotype. Mol. Plant-Microbe Interact. 15:501-510.

Gardner, P. R., and Fridovich, I. 1991. Superoxide sensitivity of the Escherichia coli aconitase. J. Biol. Chem. 266:19328-19333.

Girard, L., Valderrama, B., Palacios, R., Romero, D., and Dávila, G. 1996. Transcriptional activity of the symbiotic plasmid of Rhizobium etli is affected by different environmental conditions. Microbiology 142:2847-2856.

Gonzalez, V., Santamaria, R. I., Bustos, P., Hernandez-Gonzalez, I., Medrano-Soto, A., Moreno-Hagelsieb, G., Janga, S. C., Ramirez, M. A., Jimenez-Jacinto, V., Collado-Vides, J., and Davila, G. 2006. The partitioned Rhizobium etli genome: Genetic and metabolic redundancy in seven interacting replicons. Proc. Natl. Acad. Sci. U.S.A. 103:38343839 .

Greenberg, J. T., and Demple, B. 1986. Glutathione in Escherichia coli is dispensable for resistance to $\mathrm{H}_{2} \mathrm{O}_{2}$ and gamma radiation. J. Bacteriol. 168:1026-1029.

Griffith, O. W., Bridges, R. J., and Meister, A. 1978. Evidence that the gamma-glutamyl cycle functions in vivo using intracellular glutathione: Effects of amino acids and selective inhibition of enzymes. Proc. Natl. Acad. Sci. U.S.A. 75:5405-5408. 
Harrison, J., Jamet, A., Muglia, C. I., Van de Sype, G., Aguilar, O. M., Puppo, A., and Frendo, P. 2005. Glutathione plays a fundamental role in growth and symbiotic capacity of Sinorhizobium meliloti. J. Bacteriol. 187:168-174.

Hosie, A. H., Allaway, D., Galloway, C. S., Dunsby, H. A., and Poole, P. S 2002. Rhizobium leguminosarum has a second general amino acid permease with unusually broad substrate specificity and high similarity to branched-chain amino acid transporters (Bra/LIV) of the ABC family. J. Bacteriol. 184:4071-4080.

Huerta-Saquero, A., Calderon-Flores, A., Diaz-Villasenor, A., Du Pont, G., and Duran, S. 2004. Regulation of transcription and activity of Rhizobium etli glutaminase A. Biochim. Biophys. Acta 1673:201-207.

Kosower, N. S., and Kosower, E. M. 1995. Diamide: An oxidant probe for thiols. Methods Enzymol. 251:123-133.

Lodwig, E. M., Hosie, A. H., Bourdes, A., Findlay, K., Allaway, D., Karunakaran, R., Downie, J. A., and Poole, P. S. 2003. Amino-acid cycling drives nitrogen fixation in the legume-Rhizobium symbiosis. Nature 422:722-726.

Masip, L., Veeravalli, K., and Georgiou, G. 2006. The many faces of glutathione in bacteria. Antioxid. Redox Signal 8:753-762.

Meister, A. 1988. Glutathione metabolism and its selective modification. J. Biol. Chem. 263:17205-17208

Mora, J. 1990. Glutamine metabolism and cycling in Neurospora crassa. Microbiol. Rev. 54:293-304.

Muglia, C., Comai, G., Spegazzini, E., Riccillo, P. M., and Aguilar, O. M 2008. Glutathione produced by Rhizobium tropici is important to prevent early senescence in common bean nodules. FEMS (Fed. Eur. Microbiol. Soc.) Microbiol. Lett. 286:191-198.

Patriarca, E. J., Taté, R., and Iaccarino, M. 2002. Key role of bacterial $\mathrm{NH}_{4}{ }^{+}$metabolism in Rhizobium-plant symbiosis. Microbiol. Mol. Biol. Rev. 66:203-222.

Pauly, N., Pucciariello, C., Mandon, K., Innocenti, G., Jamet, A., Baudouin, E., Herouart, D., Frendo, P., and Puppo, A. 2006. Reactive oxygen and nitrogen species and glutathione: Key players in the legume-Rhizobium symbiosis. J. Exp. Bot. 57:1769-1776.

Riccillo, P. M., Muglia, C. I., de Bruijn, F. J., Roe, A. J., Booth, I. R., and
Aguilar, O. M. 2000. Glutathione is involved in environmental stress responses in Rhizobium tropici, including acid tolerance. J. Bacteriol. 182:1748-1753.

Sartorius, M., Riccio, A., Cermola, M., Casoria, P., Patriarca, E. J., and Taté, R. 2009. Sulphadimethoxine inhibits Phaseolus vulgaris roo growth and development of $\mathrm{N}$-fixing nodules. Chemosphere 76:306312 .

Shibayama, K., Wachino, J., Arakawa, Y., Saidijam, M., Rutherford, N. G. and Henderson, P. J. 2007. Metabolism of glutamine and glutathione via gamma-glutamyltranspeptidase and glutamate transport in Helicobacter pylori: Possible significance in the pathophysiology of the organism. Mol. Microbiol. 64:396-406.

Sobrevals, L., Muller, P., Fabra, A and Castro, S. 2006. Role of glutathione in the growth of Bradyrhizobium sp. (peanut microsymbiont) under different environmental stresses and in symbiosis with the host plant. Can. J. Microbiol. 52:609-616.

Spaink, H. P., Okker, R. J. H., Wijffelman, C. A., Pees, E., and Lugtenberg, B. J. J. 1987. Promoters in the nodulation region of the Rhizobium leguminosarum Sym plasmid pRL1J1. Plant Mol. Biol. 9:27-39.

Taté, R., Riccio, A., Iaccarino, M., and Patriarca, E. J. 1997. A cysG mutant strain of Rhizobium etli pleiotropically defective in sulfate and nitrate assimilation. J. Bacteriol. 179:7343-7350.

Taté, R., Riccio, A., Merrick, M., and Patriarca, E. J. 1998. The Rhizobium etli amtB gene coding for an $\mathrm{NH}_{4}{ }^{+}$transporter is down-regulated early during bacteroid differentiation. Mol. Plant-Microbe Interact. 11:188198.

Taté, R., Ferraioli, S., Filosa, S., Cermola, M., Riccio, A., Iaccarino, M., and Patriarca, E. J. 2004. Glutamine utilization by Rhizobium etli. Mol. Plant-Microbe Interact. 17:720-728.

Walshaw, D. L., and Poole, P. S. 1996. The general L-amino acid permease of Rhizobium leguminosarum is an ABC uptake system that also influences efflux of solutes. Mol. Microbiol. 21:1239-1252.

Walshaw, D. L., Wilkinson, A., Mundy, M., Smith, M., and Poole, P. S. 1997. Regulation of the TCA cycle and the general amino acid permease by overflow metabolism in Rhizobium leguminosarum. Microbiology 143:2209-2221. 